\title{
A Developing World Perspective on the Design of Wireless Enabled Humanitarian Relief Services
}

\author{
Anshuman Saxena ${ }^{1,2}$ \\ ${ }^{1}$ Systemic Modeling Laboratory \\ I\&C, EPFL CH 1015 Switzerland \\ ${ }^{2}$ TCS Innovation Labs, Bangalore India \\ +41216936626 \\ anshuman.saxena@epfl.ch
}

\author{
Alain Wegmann \\ Systemic Modeling Laboratory \\ I\&C, EPF Lausanne \\ $\mathrm{CH} 1015$ Switzerland \\ +41216934381 \\ alain.wegmann@epfl.ch
}

\begin{abstract}
In the absence of adequate state support, societies in the developing world have long relied on community support for humanitarian relief. Such community networks provide a readily available platform for delivery of humanitarian relief services. Wireless technologies can play an important role in enabling humanitarian relief applications that strengthen these community networks by facilitating the flow of information amongst the community members. Nevertheless, given the welfare nature of the activity, these applications face some strict design constraints that emerge from the larger socio-political-economic landscape. This paper presents a systematic approach to unearth the requirements that these domains may impose on the design of wireless enabled information and communication oriented humanitarian relief services, wiHRS. We describe SEAM, a systems thinking inspired conceptual framework that provides the theoretical underpinnings of the modeling apparatus used in this paper. As an example, we demonstrate the relevance of this framework to the design of wiHRS by analyzing the economics of enhanced information flow in community networks and how this analysis can be exploited to reflect on the financial viability of such services by, say, soliciting support from financial risk management instruments like insurance schemes.
\end{abstract}

\section{Categories and Subject Descriptors}

H.1.1 [Models and Principles]: Systems and Information Theory - General systems theory, value of information, D.2.1 [Software Engineering]: Requirements/Specifications - Elicitation methods, D.2.10 [Software Engineering]: Design - Methodologies, C.2.3 [Computer-Communication Networks]: Network Operations Public Networks.

\section{General Terms}

Design, Economics.

\section{Keywords}

Systems Thinking; Economics of Information; Risk Management.

Permission to make digital or hard copies of all or part of this work for personal or classroom use is granted without fee provided that copies are not made or distributed for profit or commercial advantage and that copies bear this notice and the full citation on the first page. To copy otherwise, or republish, to post on servers or to redistribute to lists, requires prior specific permission and/or a fee.

ACWR '11, December 18-21 2011, Amritapuri, Kollam, Kerala, India. Copyright 2011 ACM 978-1-4503-1011-6/11/12\$10.00.

\section{INTRODUCTION}

The developed world approach to humanitarian relief is build around public institutions. The state takes on bulk of the responsibility to ensure the well being of its citizen. Such centralized implementation of the concept of 'welfare-state' requires two basic resources: institutions that are sensitive to humanitarian requirements of the masses; and infrastructure that allows these institutions to reach out to the masses. Nevertheless, from a developing world perspective this model of humanitarian relief may not be feasible or even effective. Unlike the developed world, the developing world states - as the term suggests - are still in the process of strengthening their institutions and improving the infrastructure. It will be time before they reach a level of preparedness that can support universal humanitarian coverage. Furthermore, over the years, states' inability to respond to the needs of its citizens has encouraged community reliance. A few common examples of community networking and the relevance of these community networks to humanitarian relief include: residents living in the same neighborhood rely on each other for information on, say, availability of public utilities, commuters rely on each other for information on road and traffic conditions, farmers relying on their fellow land holders for information on intrusions to their field, etc. Community networks, thus, present a readily available platform for delivery of humanitarian relief services (HRS). Community networks, if equipped adequately, can complement the centralized approach to humanitarian relief; especially, in addressing the last mile problem of delivery networks.

Wireless technologies can play an important role in reinforcing these community networks. Facilitating flow of information amongst the community members will empower individual citizens with the necessary information required to both contribute and benefit from community networking. The ease of deployment and support for infrastructure-less mode of operation makes wireless technologies particularly suitable for enabling community focused HRS. Nevertheless, for community networks to graduate, from a mere adhoc and necessity driven arrangement to an established platform for humanitarian relief delivery, calls for their in-situation analysis. This will help identify the set of constraints that, if adopted, will ensure the sustainability of community networks. These constraints are requirements that emerge from within the activity domain of different stakeholder groups. It is, therefore, important to identify these stakeholder groups and surface the underlying challenges they present in a systematic manner. A holistic understanding of the design space will help engineer information and communication (ICT) specific 
requirements from the above challenges thereby resulting in an effective and sustainable wireless enabled information and communication based humanitarian relief service (wiHRS).

In this paper we present a conceptual modeling framework SEAM [1]. For any given phenomenon of interest, stakeholders represent entities that can either influence or are influenced by this phenomenon. Phenomena in the real world usually have multiple stakeholders. These stakeholders together represent a wide variety of expectations that motivate the stakeholders to take on different roles - contributing to different aspects of the phenomenon at, possibly, different stages of the lifecycle of the phenomenon. An important modeling construct in SEAM is the notion of Value Network (VN). VNs are stakeholder groups that are created based on the similarity of roles the stakeholder may undertake. In the context of wiHRS, community network can be modeled as a VN representing citizen groups. Similarly, other VNs active in the wiHRS include information service providers, different state agencies related to disaster management and relief. The concept of VN helps to reduce the number of actors by partitioning the design space of a multi-stakeholder system into similar-interest groups. Another important aspect in SEAM is to help understand the interactions between the different VNs constituting a system. A system is a set of interrelated components such that the systemas-a-whole is more than the sum of its individual components. In SEAM, this is accomplished using a value driven, input-output model of exchange and is referred to as Multi-party relationship, MPR [2]. MPR assigns two categories of roles to each participating VN - the supplier role and the adopter role. These roles describe the what-and-how of, both the contributions each $\mathrm{VN}$ makes to the relation and the benefits the $\mathrm{VN}$ receives by virtue of its participation to this relation. An important aspect of MPR is to identify how the creation, delivery and consumption of a service results in value creation for participating VNs. Using MPR one can examine if adequate value is being generated for each participating VN. It is only when the requirements emanating from the different VNs are adequately met that the underlying service or product can be deemed sustainable [3]. Using MPR we model community networks as both provider of information and consumer of information. For the underlying wiHRS to be sustainable it should deliver adequate value to each $\mathrm{VN}$ in the humanitarian space. For example, one value for state agencies is that the wiHRS ensures universal humanitarian coverage; another value for service providers is that the cost of the service is recoverable; etc.

For further exposition, we apply the proposed conceptual modeling technique to identify the requirements that need to be met to ensure the financial viability of a wiHRS. Financial viability is one of the many sustainability requirements; this one in particular sought by the members of the service provider VN. The service provider VN includes all technical and non-technical enterprises that play a role in the design, development and delivery of the service. Different approaches to financial viability can be considered - government sponsored schemes, citizen recoverable schemes, philanthropic endeavors, etc. Nevertheless, in this era of liberalized market driven economies, financial viability of a product or service is best guaranteed if market governed instruments of financing are used. The critical, temporary, urgent, and infrequent, nature of humanitarian crisis represents risk, hence we include risk managing financial institutions as part of the service provider VN. Financial instruments, e.g. insurance policies, have for long played a key role in managing risk. An insurance policy is a contract between the insurer and insured, whereby the insured is entitled to financial compensation from the insurer in lieu of the damages caused for reasons negotiated in the contract. Nevertheless, for the sake of their own financial viability, insurers extend coverage only for perils where the total risk is less than the sum of individual risks. High individual risk ensures that there are enough takers for a given insurance scheme while low total risk ensures that the net liability on the insurer remains low. Availability of information plays an important role in influencing the insurer to extend coverage to desired situations. Centralized approach to humanitarian relief presents the state as one single nodal agency and is hence easier for insurers to analyze. For community focused humanitarian relief initiatives to be equally attractive for insurers it is important that wiHRS include requirements like nodality of information [4]. By admitting such issues early on in the design phase, we can ensure that the resulting service is well integrated with the existing social, political and economic landscape and thereby more sustainable than otherwise. Finally, we map these service specific requirements to specifications for wireless application design. Some of the resulting design implications include, architectural considerations, choice of communication modes, and network topology.

The remaining part of this paper is organized as follows. Section 2 describes the conceptual framework providing the modeling apparatus required to model Multi-party relationships in multistakeholder systems. Section 3 operationalizes this framework from a risk management perspective and examines the economics of information flow in community networks. Section 4 discusses the mapping of service level requirements identified in earlier sections to specific applications of wireless technologies. Section 5 highlights the interdisciplinary nature of this work and points to relevant works in related fields. The paper ends with Section 6, which presents some open research challenges and prospective avenues for future research in the design of wiHRS.

\section{THE CONCEPTUAL FRAMEWORK}

Humanitarian relief is the central activity of any 'welfare-state'. Nevertheless, the high human quotient of this endeavor, and the diversity of interests this human involvement brings to it, makes the overall HRS design process particularly complex. In this section, we present a conceptual modeling framework, SEAM, which helps to model the interactions between the different stakeholders as a multi-party relationship. This approach helps to surface the implicit assumptions that motivate stakeholder interests thereby making them available for appropriate design considerations.

The SEAM framework is built on the principles of General Systems Thinking (GST) [5]. GST advocates that the component parts of a system can be best understood in the context of relationships with each other and with other systems, rather than in isolation. An important way to fully analyze a system is to understand the part in relation to the whole. SEAM represents any perceived reality as a hierarchy of systems. Each system can be analyzed as a whole [W] - showing its externally visible characteristics or as a composite [C] - showing its' constituents as a set of interrelated parts. In the context of this work, the following two SEAM concepts are most relevant. Meanwhile, the visual syntax of SEAM includes block arrows for systems, annotated ovals for externally visible properties, diamonds for relations, simple lines for active participation to a relation, dashed lines for pseudo participation to a relation and rounded end-point lines for emphasizing the identical nature of modeling elements. 


\subsection{Value Network}

The concept of $\mathrm{VN}$ exploits the similarity of intent among the different stakeholders. $\mathrm{VN}$ is a grouping of stakeholders cooperating to achieve a common objective. Identifying VNs helps to reduce the design space and is particularly useful for activities with large number of stakeholders. The concept of VN does not result in any loss of generality of the design space. Individual stakeholders, who lack like-minded company, can also be instantiated as a VN. The granularity of stakeholder grouping is a modeling choice that should be made based on the issues under consideration.

In the humanitarian relief space, the following four VNs seem to be well representative of the challenges we intend to highlight: the Service Provider VN, which refers to the set of stakeholders that work together to design, implement, deliver and maintain a wiHRS; the Citizen VN, or community network, which refers to citizens that benefit from the shared use of a wiHRS; the State $\mathrm{VN}$, which refers to the different institutions that constitute the administrative, legal and constitutional machinery of a state; and the Environment VN, which constitutes all the remaining stakeholders that participate indirectly to the realization or consumption of a wiHRS. The Environment $\mathrm{VN}$ is particularly interesting as it exposes any externalities generated during the entire lifecycle of a wiHRS. It is the inclusion of the Environment $\mathrm{VN}$ that lends externalities a first class design perspective along side other more established perspectives emanating from the supplier, consumer and legal domains.
Fig. 1 provides a SEAM depiction of the design space for humanitarian relief from landslides. The primary activity of interest here is to deliver humanitarian relief to $\mathrm{Mr}$. $\mathrm{X}$ and his family who seek humanitarian relief from landslides. This relief is delivered through the adoption of a wiHRS that is provided by the Service Provider VN. The Service Provider VN includes a device manufacturer, network provider and system integrator - together these stakeholders provide the ICT infrastructure required to implement the technical aspects of the service. The resulting technical service is integrated with the community network, which, as an example, is shown to be composed of Mr. X, Mr. Y and Mr. Z. Presence of Mr. X both, in the Citizen VN and in the Community Network shows that citizens participate to a community network from which they themselves also benefit. Mr. $\mathrm{Y}$ and $\mathrm{Mr} . \mathrm{Z}$ are other members of this Community Network who, in this figure, are only shown to contribute to the realization of community network and not benefit from the use of the wiHRS, Mr. Y and Mr. Z along with another Mr. J constitute the Environment VN in which Mr. X uses the wiHRS. It is important that the use of wiHRS does not result in any externalities for other members of the community network, Mr. Y and Mr. Z, or any citizen outside the community network, Mr. J. The wiHRS is implemented and consumed under a set of guidelines provided by the state. The State VN includes various agencies of the administrative machinery related to surface transport - Regional Transport Office and Public Works Department; law \& order Policy; and crisis response - Disaster Management Agency.

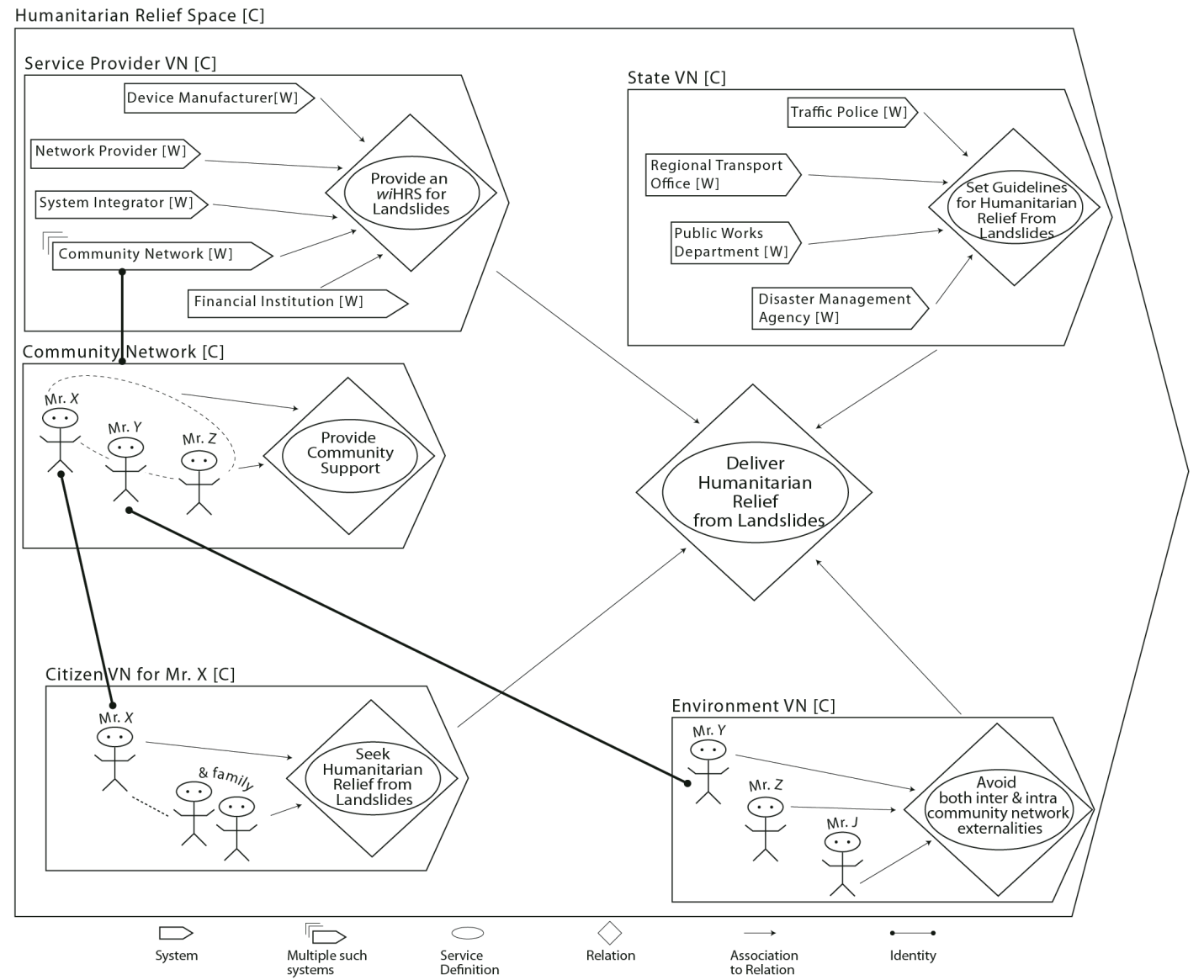

Figure 1. Design space for humanitarian relief from landslides. 


\subsection{Multi-Party Relationship}

The concept of Multi-Party Relationship (MPR) is based on the basic tenet of Systems theory, which states that the whole is more than just the sum of its constituent parts. As the name suggests, MPR models domain activity as an n-ary relationship with ' $n$ ' being the number of VNs participating in that activity. Such a modeling of activity allows for an in-context investigation of VNs. This is accomplished using an input-output model, which posits that entities participate to an activity only if they have something to contribute to it and something to gain from it. This equality in surfacing both the contributions by a $\mathrm{VN}$ to an activity and expectations of the VN from the activity provides a good basis to reason about the sustainability of the activity.

Fig. 2 lists the contribution and expectation of each $\mathrm{VN}$ in the humanitarian relief space. The Service Provider VN implements the wiHRS and in lieu of this contribution, it expects a return on investment. Citizens like Mr. X seek relief from humanitarian crisis. They benefit from the availability of wiHRS. In return, the humanitarian relief space values his participation to the community networks. Since the welfare of citizens is a ultimately a state subject, the state publishes guidelines to ensure their collective welfare. Typical expectations of the state from wiHRS include neutrality of content being shared, impartiality in delivering information and guaranteed access to this service for anyone interested. An important benefit of following the state guidelines is the possibility of wider integration of wiHRS with elements higher up the humanitarian relief value chain, such as integration with healthcare system. All other citizens, both part of a given community network but not currently benefiting from the wiHRS and outside of the community network, constitute the Environment VN. Some of these citizens contribute directly to the relief efforts by virtue of their participation to the community network or indirectly by staying mindful of community concerns. For these citizens to continue their positive contribution to wiHRS it is required that they are safeguarded from any spill over effects of the different phases of the wiHRS lifecyle. Some of the known effects are externalities in the form of social exclusion resulting because of the citizen's non-membership of a community network or the compromise of trust that the citizens place on their community networks.

Identifying the expectations of a stakeholder and the contributions it can make to some target activity can very easily degenerate into an endless exercise in scope refinement. To contain this we employ the heuristic of closure. During the course of investigation, whenever the total set of contributions identified from all stakeholders are enough to realize the total set of expectations of all stakeholders, the investigation is said to be in a state of closure. An investigation can be in a state of closure multiple times. When in a state of closure, it is a design choice to either accept the current set of contributions and expectations as representative of the actual situation being modeled or there is a need to further refine the scope. We consider the analysis depicted in Fig. 2 to be in a state of closure and accept the set of contributions and expectations listed therein as well representative of the multi-stakeholder environment that constitutes the HRS.

From a requirements specification point of view, the focus is on the set of expectations. In their current form, these expectations represent domain specific considerations. Identifying application level requirements from these expectations calls for a mapping of these subjective considerations to an implementable service specification. In the context of design of wiHRS, we focus only on the information and communication related service specifications. Given the diversity of stakeholder interests, the requirements that

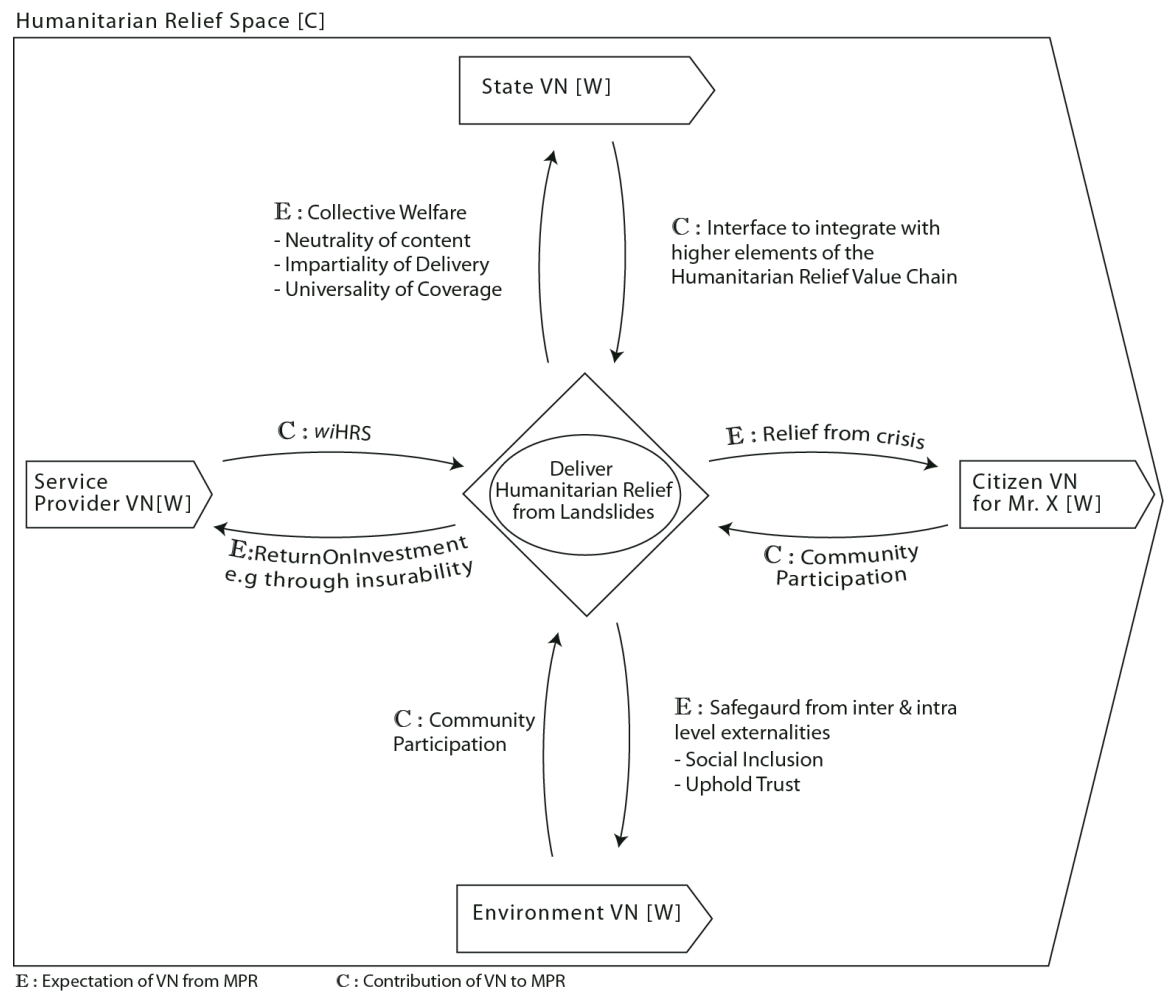

Figure 2. Design constraints on wiHRS. 
the different stakeholder expectations may impose on the service may not always be easy to compose. To resolve any conflicts during the mapping of stakeholder expectations to information and communication requirements, we study the different aspects of information creation, dissemination and consumption. The following section takes this study forward by looking at these issues in greater detail.

\section{ECONOMICS OF INFORMATION}

As noted by the noble laureate for economics in the year 1970, Paul Samuelson, economics is the study of understanding the "What, how and for whom" of a product or service. Thus any effort to delineate the economics of information should seek to characterize information - as to what constitutes information, reflect on the feasibility of the infrastructure required to gather, analyze and disseminate information - as to how such a service will come into being, and identify the benefits it will bring to the different stakeholders of the service - as to who all will be affected.

Given the information and communication oriented nature of wiHRS, understanding the economics of information that the service aims to further will provide important design considerations for the service. To accomplish this we refine the conceptual model developed in Section 2 by specifying the contribution and expectation in terms of information. To make the discussion more concrete, we restrict our focus on the Service Provider VN. In the following we present a characterization of community networks. Each type of community network is instantiated as a different VN within the Service Provider VN. One major expectation that the Service Provider VN has is to ensure decent return on its investments (RoI) in developing the wiHRS. One can investigate the suitability of different financial instruments in ensuring sustained RoI. Given the closeness of humanitarian field to risk management, as an example, we choose to focus only on one of the financial instruments from the risk management portfolio - i.e. insurance as a means to finance wiHRS. It is worth nothing that the example of insurance, though very much practical, has only illustrative significance in this paper. This is only to show how different actors in the design space may impose diverse and often, conflicting constraints on the design of wiHRS and how those design constraints can be surfaced in a systematic manner.

\subsection{Community Networks as Vehicles of Humanitarian Relief}

As per the UN charter [6], humanitarian relief can be of three types: direct, indirect and infrastructure oriented. With the same token we classify the community networks that help deliver the different types of relief and define them as follows:

Direct Relief Delivering Community Networks (diCN) are community networks, which are capable of generating, analyzing and disseminating information amongst the community members. When a diCN community member observes an event he not only reports the occurrence of that event but also his analysis to the community members. Analysis is a contextualized reporting of the event. For example, in case of landslides the $d i \mathrm{CN}$ member will not only report that there has been a landslide but also how much time he thinks it will take for the roads to be cleared. Such reporting points to a higher level of trust between the community members, which forms the basis for the reporter to be confident about the interests of his community members and the other community members to be confident in his reporting.

Indirect Relief Delivering Community Networks (idCN) are community networks, which are capable of generating and disseminating information amongst the community members. $i d \mathrm{CNs}$ differ from the diCNs in the sense that community members report events to other community members. Nevertheless, they do not enjoy enough trust amongst themselves to also share their interpretations of the event.

Infrastructure Supporting Community Networks (inCN) are community networks, which are only capable of disseminating information amongst the community members. Members of these networks are loosely connected to each other and any communication amongst them is of querying nature. The level of trust here is minimal amongst the three categories.

Table 1. A humanitarian relief oriented classification of community networks

\begin{tabular}{|l|l|l|l|}
\hline $\begin{array}{l}\text { Type of } \\
\text { Community } \\
\text { Network }\end{array}$ & $\begin{array}{l}\text { Trust } \\
\text { Level }\end{array}$ & Content & $\begin{array}{l}\text { Communication } \\
\text { Mode }\end{array}$ \\
\hline$d i \mathrm{CN}$ & High & Contextualized & Push/Pull \\
\hline$i d \mathrm{CN}$ & Medium & Raw & Push/Pull \\
\hline$i n \mathrm{CN}$ & Low & None & Pull \\
\hline
\end{tabular}

\subsection{Risk Management Perspective}

In this era of liberalized market driven economies an important aspect of sustainable design is to allow market forces regulate the financial viability of any product or service. The critical, temporary, urgent, and infrequent, nature of humanitarian crisis presents some serious questions about recovering the cost of design, development and maintenance of HRS. The community network oriented implementation of HRS is not just functionally effective but also cost effective. Nevertheless, the financial viability of these community networks still needs to be investigated. For instance, in the case of Internet of Things based service the initial device procurement may be one major cost factor in establishing community networks. In this section we highlight the risk aspect of humanitarian crisis and investigate the design constraints that existing risk management techniques like insurance schemes may impose on the wiHRS.

A risk is insurable if the following three conditions are met: (1) Potential loss to individuals is significant enough to motivate them to look for hedging options such as purchase of insurance policy etc. (2) The amount of loss is well defined and outside the influence of the insured (3) Covered Losses should be reasonably independent. In the context of humanitarian crisis, the first two requirements of insurability are inherent in the risk such crisis present. It is the third option that needs further investigation. To make the treatment concrete, let us first see where do the different $\mathrm{CNs}$ stand on the requirement of losses being independent. 


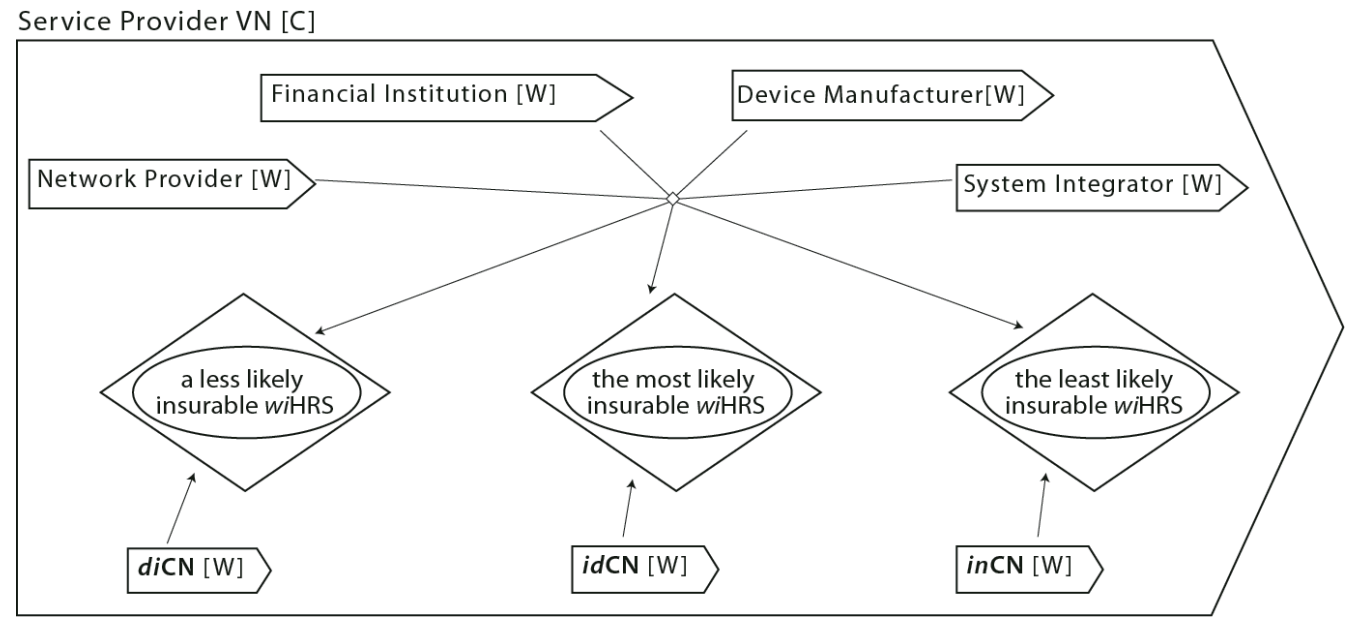

Figure 3. Insurability of wiHRS for different community networks

In $\mathrm{diCN}$ an event is reported to the community members in the processed form i.e. as an implication of the event in a given context. Revisiting the earlier example, in the context of travel between two cities, the event of road being blocked due to landslide will be reported as delay on that route. Given the high level of trust amongst the community members we assume that each member shares interest in the same context and that it responds positively to the information received, lets say, cancelling the trip. Though the actual response to crisis depends on the correctness of information, but more interestingly, in this case, the risk to individual members is no more independent. Since they all rely on one unique interpretation made by the reporting member, they respond to the crisis in the same manner.

In $i d \mathrm{CN}$ an event is reported to the community members as such. Each community member interprets the report in light of its own context. Note that the low level of trust between the members of $i d \mathrm{CN}$ opens the possibility of each member interpreting the reported event in a different context. As a result the response from each member may be different, suggesting the independence of risk to each member.

In in $\mathrm{CN}$ no events are reported proactively. The members of the community share a communication infrastructure but an even lower level of trust that the other two CNs impedes any proactive information dissemination. An event observed by any community member will not be reported unless it is specifically queried for. Such lack of flow of information in inCNs makes it very difficult to evaluate its suitability for insurance like schemes.

At the heart of evaluating the insurability of the service is the availability of information so that the insurer can make an informed decision. Centralized approach to humanitarian relief presents the state as one single nodal agency and is hence easier for insurers to analyze. For community focused humanitarian relief initiatives to be equally attractive for insurers it is important that wiHRS include requirements like nodality of information. We discuss the implications of this in the next section and map the information requirements to specific design constraints on the use of wireless technologies in wiHRS.

\section{DISCUSSION: REQUIREMENTS SPECIFICATION}

On a more practical note, the question this paper attempts to answer is the following: How do the different design choices made during the development of a wiHRS affect the insurability of the risk that the humanitarian crisis presents?

Such questions represent a broader class of problems on sustainable service design in multi-stakeholder systems. The choice of insurability as a representative design criterion for exposition is in line with the importance financial viability enjoys among other design constraints. Nevertheless, the approach developed in this paper is in no way limited to any specific domain. Further, to make the example truly representative of multi-stakeholder systems, we expose the insurability constraints to two additional sets of constraints - one emanating from the guidelines set by states for delivery of humanitarian relief, such as neutrality, impartiality and universality of coverage; second emanating from citizen groups that may not be directly benefiting from the service and may or may not be part of the community network, such as social inclusion and upholding community trust. Mapping these constraints on to the information plane may yield conflicting requirements on the application of information and communication technologies. Table II presents a mapping of domain constraints to application requirements.

As discussed in the earlier section, lack of bias in reporting an event makes id $\mathrm{CN}$ more insurable than others. Nevertheless, the insurer will still like to propagate correct opinions about an event so that the community members can benefit from others expertise. This will also bring the overall claims down. From a communication point of view, this calls for both flat and multilevel communication pattern. In a multi-level approach the event can be reported first to expert members who can in turn share their expert opinion with all. This, however, may seem contradictory to the neutrality of content requirement imposed by the state where in every event is reported as such without any qualified remarks. One way to avoid such conflict could be report raw content i.e. reporting of occurrence of event to all and let the recipient community member decide if community members can contribute to its interpretation. Similarly, to ensure impartiality of delivery any push of information, such as event reporting, should always 
Table 2. Mapping domain constraints to requirements specification

\begin{tabular}{|c|c|c|c|c|c|c|}
\hline \multirow{2}{*}{$\begin{array}{l}\text { Stakeholder } \\
\text { Group }\end{array}$} & \multirow{2}{*}{ Motivation } & \multirow{2}{*}{$\begin{array}{l}\text { Domain } \\
\text { Constraints }\end{array}$} & \multicolumn{4}{|c|}{ Wireless Application Requirements } \\
\hline & & & $\begin{array}{l}\text { Network } \\
\text { Topology }\end{array}$ & $\begin{array}{l}\text { Security } \\
\text { Setting }\end{array}$ & $\begin{array}{l}\text { Communicatio } \\
\text { n Mode }\end{array}$ & $\begin{array}{l}\text { Communication } \\
\text { Pattern }\end{array}$ \\
\hline $\begin{array}{l}\text { Service } \\
\text { Provider VN }\end{array}$ & Insurability & $\begin{array}{l}\text { Independence } \\
\text { of loss from } \\
\text { crisis }\end{array}$ & - & - & - & $\begin{array}{l}\text { Support for both } \\
\text { multi-level and } \\
\text { flat }\end{array}$ \\
\hline \multirow[t]{2}{*}{ State VN } & \multirow{2}{*}{$\begin{array}{l}\text { Collective } \\
\text { welfare }\end{array}$} & $\begin{array}{l}\text { Neutrality of } \\
\text { Content }\end{array}$ & - & - & - & $\begin{array}{l}\text { Support for only } \\
\text { flat }\end{array}$ \\
\hline & & $\begin{array}{l}\text { Impartial } \\
\text { Delivery }\end{array}$ & - & - & $\begin{array}{l}\text { Broadcast of } \\
\text { messages }\end{array}$ & - \\
\hline \multirow{2}{*}{$\begin{array}{l}\text { Environment } \\
\text { VN }\end{array}$} & \multirow{2}{*}{$\begin{array}{l}\text { Avoid } \\
\text { Externalities }\end{array}$} & $\begin{array}{l}\text { Social } \\
\text { Inclusion }\end{array}$ & $\begin{array}{l}\text { Gateway } \\
\text { functionality }\end{array}$ & - & - & - \\
\hline & & Uphold Trust & - & $\begin{array}{l}\text { Anonymity of } \\
\text { communication }\end{array}$ & - & - \\
\hline
\end{tabular}

be broadcasted. Another important implementation issue could be the need to include the gateway functionality. Citizen outside the community member should also be able to benefit from community member if any community member has out of band communication channel with the external members. This out of band communication channel can be any communication interface other than the one available within the community members - for example in the event that community network is cellular powered, the external member only has wifi connectivity. In this case the gateway functionality can help community members with both wifi and cellular to channel information to the external members too and thereby achieve social inclusion. Another important issue is the upholding of trust that the community members enjoy among themselves. Appropriate security settings might be required to safeguard community member's anonymity so that he can continue to enable the community network.

To conclude, this paper has highlighted four important conceptual modeling issues in the study of sustainable service design in multi-stakeholder systems.

- Design Space Formalization and Reduction

- Symmetric Aspect of Value Exchange

- Closure Heuristic as an Aid for Design Space Scoping

- Compositional Aspect of Requirements Specification

An approach following the above guidelines of systemic investigation allowed us to develop a comprehensive model of the humanitarian relief space and situate it in a developing world context. While acknowledging the limitation of the developing world in adopting a developed world model of humanitarian relief, we highlighted the spirit of community living as an alternate vehicle for delivering humanitarian relief. Various aspects of information flow in community networks were investigated and their relevance to the implementation of wireless enabled information and communication oriented humanitarian relief services was mapped.

\section{RELATED WORK}

The fast pace of advancements in wireless technologies has left industry practitioners way behind. Today, the primary challenge in developing a wireless enabled solution is no more the wireless technology itself; it is the understanding of the ecosystem in which the application will be put to use. For instance, in a relatively recent field of Internet of Things (IoT) a large number of successful proof-of-concept systems have been demonstrated [7], which not only establish the maturity of the underlying technology but also the prospective benefits it can bring to a plethora of human activity, including humanitarian relief. Unfortunately though, these proof-of-concept systems do not seem to translate into large-scale systems of daily use. The Smart Grid initiative is, one initiative where a large-scale deployment of such interconnected systems is underway [8]. One of the components required to realize the Smart Grid system is a smart meter. Smart meters installed at the point of electricity consumption measure the flow of electricity and report the same in real-time, over-the-air to the concerned Utility Company. Increasingly, these smart meters are courting controversy with fears ranging from sustained exposure to radiation leading to brain cancer to the state's big-brother-attitude provoked privacy concerns of hosting a homing device [9]. It is clear that not all aspects of the Smart Grid ecosystem were given enough attention while rolling out smart meter services.

Studies aimed at understanding the larger environment of a system are not new. In fact, Requirements Engineering (RE), a sub discipline of systems engineering and software engineering [10], is aimed at identifying the desired properties of a given system thereby enabling its implementation as an Information and Communication Technologies ICT system [11]. An RE process is composed of the following four phases: feasibility study, requirements analysis, requirements definition and requirements specification [12]. Over the years, the RE community has developed a variety of artifacts that address the numerous research challenges these tasks present [13][14].

The challenge then is not so much about having the right requirements engineering know-how but the motivation to do a genuine systemic analysis of the design space, giving equal 
credence to issues of legal, economic and social domains. The larger question this observation then poses is, which institution, individual or group, if any, amongst the set of identified stakeholders is interested in the overall sustainability of the target system. Many activity domains have established institutions just for this purpose, e.g. regulatory bodies for public utilities. A closer examination, though, reveals that such institutions very often get bogged down with other more mundane things and loose sight of the original mandate [15] [16]. This responsibility of systemic oversight then falls on the invisible hand of the market [17]. It is in this context that we highlighted the insurability aspect of wiHRS as a constraint to ensure market sensitive viability of humanitarian relief services.

\section{FUTURE WORK}

As part of our future work in this area, we intend to further our investigation in understanding the economics of information that underlie different applications of IoT paradigm in realizing ICT for development (ICT4D) projects. An important aspect of this work will be to examine the suitability of financial instruments like subsidy, loans, insurance, rent, etc, for different class of ICT4D projects.

\section{REFERENCES}

[1] Wegmann, A., Julia, P., Regev, G., and Rychkova, I. 2007. Early Requirements and Business-IT Alignment with SEAM for Business. In Proceedings of the IEEE International Requirements Engineering Conference (Delhi, India 2007). IEEE Press, 111-114.

[2] Saxena, A. and Wegmann, A. 2010. A Systemic Design of Regulation Enabling Ontology. In Proceedings of the International Conference on Knowledge Engineering and Ontology Development (Valencia, Spain, October, 2007).
[3] World Commission on Environment and Development. 1987. Our Common Future. Oxford University Press, UK.

[4] Hood, C. and Margetts, H. 2007. The Tools of Government in the Digital Age. Palgrave Macmillan, London.

[5] Weinberg. G. 1975. An Introduction to General System Thinking. Wiley \& Sons, New Jersey, USA.

[6] United Nations Office for the Coordination of Humanitarian Affairs. 2011. http://www.unocha.org/

[7] J. K. Romer and F. Mattern, "The Design Space of Wireless Sensor Networks," In Proceddings of the IEEE Wireless Communications, Vol. 11, No. 6. Dec. 2004, pp. 54-61

[8] IEEE Smart Grid Portal. 2011. http://smartgrid.ieee.org.

[9] Zachary, G. 2011. Saving Smart Meters from a Backlash. IEEE Spectrum (August 2011).

[10] Laplante, P. 2009. Requirements Engineering for Software and Systems. CRC Press, Redmond, WA.

[11] Gause, D. and Weinberg, G. 1989. Exploring Requirements: Quality Before Design. Dorset House Publishing, New York, USA.

[12] Sommerville, I. 2006. Software Engineering: Update. Pearson Education, New Jersey, US.

[13] Cheng, B. and Atlee, J. 2007. Research Directions in Requirements Engineering. In Proceedings of the Future of Software Engineering, (Washington DC, USA, 2007). IEEE Computer Society, 285-303.

[14] Zave, P. 1997. Classification of Research Efforts in Requirements Engineering. ACM Computing Survey 29 (1997), 315-321.

[15] Baldwin, R. and Cave, M. 1999. Understanding Regulation: Theory, Strategy and Practice. Oxford University Press, Oxford, UK.

[16] Christainsen, G. and Haverman, R. 1981. The Public Regulation and the Slow-Down in Productivity Growth. American Economic Review, 320-325.

[17] Smith, A. 1904. Wealth of Nations. Methuen, London, UK. 